\title{
BACTERIOLOGICAL QUALITY OF BOTTLED WATER SOLD ON THE GHANAIAN MARKET
}

Addo KK ${ }^{* 1}$, Mensah GI ${ }^{1}$, Donkor $B^{1}$, Bonsu $C^{1}$ and ML Akyeh ${ }^{1}$

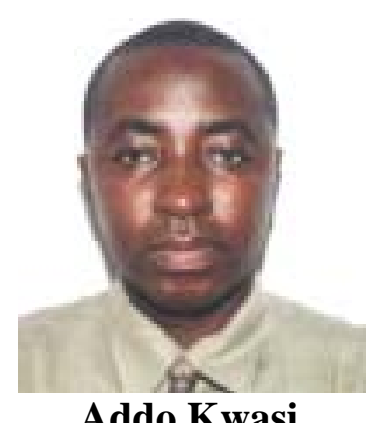

*Corresponding author email: kaddo@noguchi.mimcom.org

${ }^{1}$ Bacteriology Department, Noguchi Memorial Institute for Medical Research, University of Ghana, P. O. Box LG 581, Legon-Accra, Ghana. 


\begin{abstract}
Consumption of bottled water is increasing rapidly in developing countries especially among the middle and high income earners as it is generally perceived to be pure, clean and of good quality. This has led to the sale of different brands of bottled water on the Ghanaian market. Although disease outbreaks due to contaminated bottled water are rare, any contamination may pose a unique hazard because of the widespread distribution. Bacteriological contamination of bottled water can occur through the bottling process or as a result of storage for long periods at room temperatures or higher. Since bottled water may be consumed by a wide range of people including the elderly, children and pregnant women, its safety must always be assured. The bacteriological quality of the current 7 brands of bottled water on the Ghanaian market was tested over a period of 10 weeks. Ten different batches of each brand was randomly selected and purchased from the market making a total of 70 samples. Sampling was done weekly in July-September 2007 and bacteriological examination conducted by multiple tube fermentation method to detect the presence of total coliforms, faecal coliforms and Escherichia coli. Results obtained were analyzed according to the World Health Organization (WHO) standards and guidelines for drinking water. Using the Most Probable Number (MPN) Index for various combination of positive and negative results, an MPN value of less than two $(<2)$ total and faecal coliform were recorded for all the 70 samples of bottled water. The results showed that the bacteriological quality of the seven brands of bottled water samples analyzed was within the acceptable limits set by WHO guidelines and therefore safe for human consumption. However, more extensive surveillance of the bottled water industries and stringent regulations should be developed and enforced to ensure that the standards recorded in this study are maintained.
\end{abstract}

Keywords: Bottled water, Coliform, E.coli 


\section{INTRODUCTION}

Bottled water is any potable water that is manufactured, distributed or offered for sale, which is sealed in food-grade bottles or other containers and intended for human consumption [1]. It is generally perceived as pure, clean, of good quality and 'protected' [2]. Sales of bottled water have increased dramatically in recent years, with worldwide sales of more than 35 billion United States dollars, largely because of the public perception of purity and safety and public concern about the quality of tap water [3].

Many bottled waters contain spring, mineral or glacial water; yet bottled water can also be manufactured from tap water. De-mineralized water or distilled water is simply tap water that has undergone processes to lower mineral content and remove chemicals such as chlorine [4]. Tap water and bottled water are virtually the same; the risks for contamination of bottled water are the same as those for tap water [5]. Although waterborne diseases associated with consumption of commercial bottled water are not common, some such cases have been reported. Bottled drinking water has been occasionally related to diarrhea conditions known as traveler's disease [6].

A survey of bottled water conducted in the United Arab Emirates, where about $90 \%$ of the population drinks bottled mineral water; showed that $40 \%$ of the bottled water was bacteriologically contaminated [7]. A study conducted in Canada by Warburton et al. [8] indicated that $46 \%$ of the domestic purified waters exceeded the Canadian bottled-water standard of 100 colony forming units per milliliter for plate counts. In Portugal, during the cholera epidemic of 1974, bottled mineral water was identified as one of the vehicles of transmission of Vibrio cholerae [9].

In Ghana, the past decade has seen a dramatic increase in the consumption of bottled water, and more especially plastic-bagged drinking water [10]. The increase in demand for these products has been attributed to changes in fashion towards the consumption of designer water, increased concerns about the safety of piped water supply and an increased influx of people into major shopping areas with a requirement for good drinking water [11, 12]. Plastic bagged water popularly known as pure water has become a more attractive source of drinking water for most Ghanaians due to its lower price compared to bottled water. Despite its popularity, studies done on bacteriological quality of sachet water in some African cities have catalogued various levels of contamination $[13,14,15]$. Bottled water thus remains the safety net as far as most consumers are concerned.

Earlier investigations conducted on the safety of drinking water in Kumasi, the second largest city in Ghana reported that bottled water was of good microbiological quality while the quality of some plastic bagged drinking water was noted to be doubtful [10]. The main objective of this study was to examine the bacteriological quality of bottled water currently available on the Ghanaian market by determining the total and faecal coliform count using the multiple tube fermentation method. 


\section{MATERIALS AND METHODS}

\section{Study/Sampling Sites}

Ten different batches of seven brands (A, B, C, D, E, F, G) of bottled water currently available on the Ghanaian market were collected randomly from the market centers in Accra between July and September 2007 and transported to the bacteriology laboratory of the Noguchi Memorial Institute for Medical Research, Legon on ice packs within hours after collection. The samples were taken through bacteriological examination immediately upon arrival.

\section{Inoculation and Incubation}

All glassware, inoculating loops and plastic micropipette were sterilized using hot air oven, Bunsen burner and autoclave respectively. The working surfaces were disinfected with $70 \%$ ethanol.

\section{Presumptive coliform count}

Fifteen culture tubes were used per sample; five tubes contained $10 \mathrm{ml}$ double strength and the remaining ten contained $5 \mathrm{ml}$ single strength MacConkey broth (Oxoid CM5a) with inverted Durham tubes. Each bottled water sample was shaken vigorously to obtain a homogenous dispersion of microorganisms and the bottle necks sterilized with $70 \%$ alcohol. With a sterile pipette (Sarstedt), $10 \mathrm{ml}$ of the water sample was aseptically dispensed into each of the five culture tubes containing the double strength broth. The tubes were gently shaken to distribute the sample uniformly throughout the media. One milliliter of it was then inoculated into each of the second five culture tubes and $0.1 \mathrm{ml}$ inoculated into the remaining five tubes all containing the single strength MacConkey broth. This procedure was repeated for all samples. Incubation was at $35^{\circ} \mathrm{C}$ for $24-48$ hours. After $24-48$ hours of incubation, the cultures were observed for the presence of acid production (color change from purple to yellow) and gas formation (displacement of medium from inverted Durham tube). The absence of both signs in all cultures gives MPN values of less than two on the McCrady table making it unnecessary for continuation to the next stage which is the confirmatory test.

\section{Confirmatory test}

Although all tubes gave negative results, a loopful of each sample from the highest dilution was inoculated into $5 \mathrm{ml}$ brilliant green lactose bile broth (BioMerieux 69260) to ascertain whether there was any faecal coliform present that could not grow in MacConkey broth. The cultures were observed for gas formation after 48 hours incubation at $35^{\circ} \mathrm{C}$.

\section{RESULTS}

Results from samples analyzed for the first week all had MPN value of less than two (>2) for total coliforms for every $100 \mathrm{ml}$ taken (Table 1). The same trend of results was recorded for subsequent weeks. In the determination of faecal coliform the same trend was observed (Table 2). 


\section{DISCUSSION}

WHO's standard for drinking water states that, "the recommended maximum acceptable concentration for total and faecal coliforms is no detectable organism per $100 \mathrm{ml}$ of water sample analyzed or no more than 1 of 10 analytical units of water sampled should have an MPN value of $<2.2 \mathrm{MPN} / 100 \mathrm{ml}$ of water [15]. All the 70 samples from the seven brands of bottled water met this criteria and could be said to be of good bacteriological quality and thus suitable for human consumption since they all recorded a value of $<2$ for total and faecal coliform, meaning there were no coliforms detected.

The results of this study compares with a similar study done in Kumasi, Ghana in which no total or faecal coliforms were detected in any of the three batches of seven brands of bottled water tested [10].

Adherence to strict quality assurance procedures in the laboratory and production floors by the various bottled water companies may have accounted for the good results obtained in this study. Some bottled water producers' source water from groundwater (deep wells and springs) with usually few microorganisms due to the filtration process as water trickles through the layers of the earth [16]. Bottled water from such a source may also be free of any coliform organisms.

Some studies done on bottled water in other countries in Africa have reported various levels of contamination. In Tanzania one hundred and thirty samples representing 13 brands of bottled water collected from shops, supermarkets and street vendors were analyzed for total coliform and faecal coliform organisms and recorded $4.6 \%$ and $3.6 \%$, respectively [17]. In a similar study in Zimbabwe, a total of sixty samples of bottled water processed locally were analyzed; four $(6.7 \%)$ and seven $(11.7 \%)$ samples were found to exceed the recommended maximum total viable and coliform counts, respectively [18]. A cross-sectional study conducted to determine the microbial quality of domestic and imported brands of bottled water available in Trinidad concluded that based on the recommended zero tolerance for coliforms in potable water, $5 \%$ of bottled water sold in Trinidad could be considered unfit for human consumption [19].

There are strict standards that prohibit the sale of bottled water containing coliforms, faecal coliforms and other pathogens [20]. In this current study total and faecal coliforms were absent which indicated the absence of faecal contamination in the samples tested (Table 2). There is however, the need for continuous monitoring of the quality of bottled water just as is done for tap water because while bottled water may meet initial bacteriological standards, the lack of residual disinfection (chlorine) and prolonged periods of storage at room temperature or higher temperature may result in elevated Heterotrophic Plate Count (HPC) by the time the water is consumed. Microbial numbers may reach a peak after a week of storage and remain fairly constant thereafter [2]. In a random survey of microbial quality of bottled water in

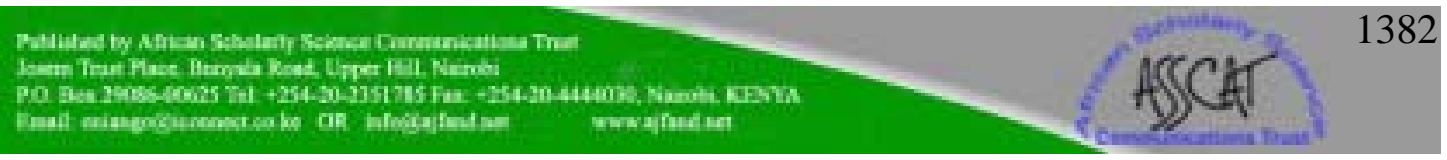


South Africa, samples from 10 different brands of bottled water were tested over a period of 3 months duration and although total and faecal coliform were not detected, HPC showed a slight variation during the three-month period [21]. Other studies have shown that high counts of E.coli in bottled water could not be detected within four days [22]. The absence might be due to die-off in the bottles during storage.

As might be anticipated, microbial quality of freshly bottled water (within 48 hours of bottling) is usually excellent. Rate of microbial change is related to a variety of factors including organic nutrient in the water that can be assimilated, competition for dominance in the microbial flora, water $\mathrm{pH}$ and storage temperature [23]. In our tropical climate bottled water that is stored at room temperature for long periods may stand the risk of contamination even though the water might eventually be sold chilled to the customer.

\section{CONCLUSION}

The study indicated that there was no bacteriological contamination (total coliform, faecal coliform or E. coli) in the selected brands of bottled water per every $100 \mathrm{ml}$ analyzed. The results obtained in this study were comparable and in agreement with similar reports by other researchers such as Obiri-Danso et al. [10] and Ehlers et al. [21], which indicates that bottled water generally met the criteria set by the WHO on drinking water quality. However, more extensive surveillance of bottled water industries and more stringent regulations should be developed and enforced to ensure that the standards recorded in this study are maintained.

\section{ACKNOWLEDGEMENT}

The authors wish to express their sincere gratitude to the staff of the Bacteriological Department of Noguchi Memorial Institute for Medical Research, University of Ghana, Legon for their effort in ensuring the success of the study. 


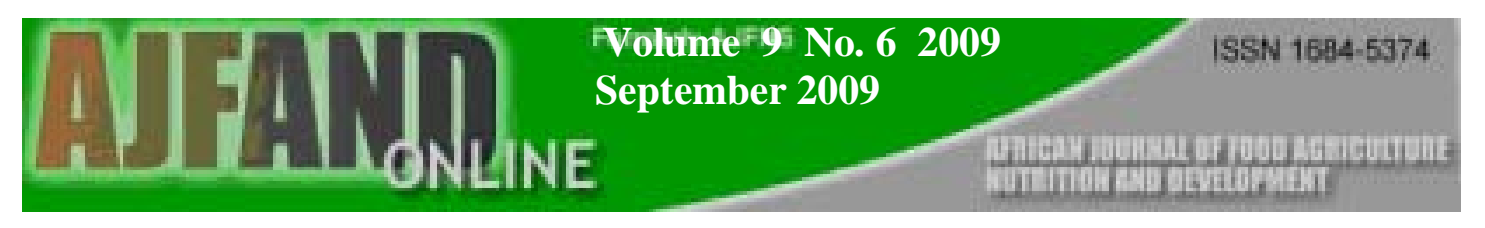

Table 1: Total Coliform Count based on Most Probable Number (MPN/100ml)

\begin{tabular}{|c|c|c|c|c|c|c|c|c|c|c|}
\hline \multirow{2}{*}{$\begin{array}{l}\text { Brand } \\
\text { of bottled } \\
\text { water }\end{array}$} & \multicolumn{10}{|c|}{ WEEK } \\
\hline & 1 & 2 & 3 & 4 & 5 & 6 & 7 & 8 & 9 & 10 \\
\hline $\bar{A}$ & $<2$ & $<2$ & $<2$ & $<2$ & $<2$ & $<2$ & $<2$ & $<2$ & $<2$ & $<2$ \\
\hline B & $<2$ & $<2$ & $<2$ & $<2$ & $<2$ & $<2$ & $<2$ & $<2$ & $<2$ & $<2$ \\
\hline $\mathrm{C}$ & $<2$ & $<2$ & $<2$ & $<2$ & $<2$ & $<2$ & $<2$ & $<2$ & $<2$ & $<2$ \\
\hline D & $<2$ & $<2$ & $<2$ & $<2$ & $<2$ & $<2$ & $<2$ & $<2$ & $<2$ & $<2$ \\
\hline $\mathbf{E}$ & $<2$ & $<2$ & $<2$ & $<2$ & $<2$ & $<2$ & $<2$ & $<2$ & $<2$ & $<2$ \\
\hline $\mathbf{F}$ & $<2$ & $<2$ & $<2$ & $<2$ & $<2$ & $<2$ & $<2$ & $<2$ & $<2$ & $<2$ \\
\hline $\mathbf{G}$ & $<2$ & $<2$ & $<2$ & $<2$ & $<2$ & $<2$ & $<2$ & $<2$ & $<2$ & $<2$ \\
\hline
\end{tabular}




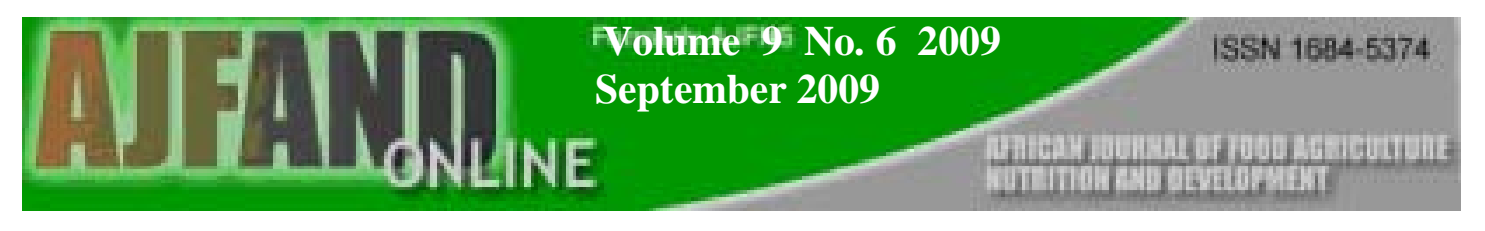

Table 2: Faecal Coliform Count based on Most Probable Number (MPN/100ml)

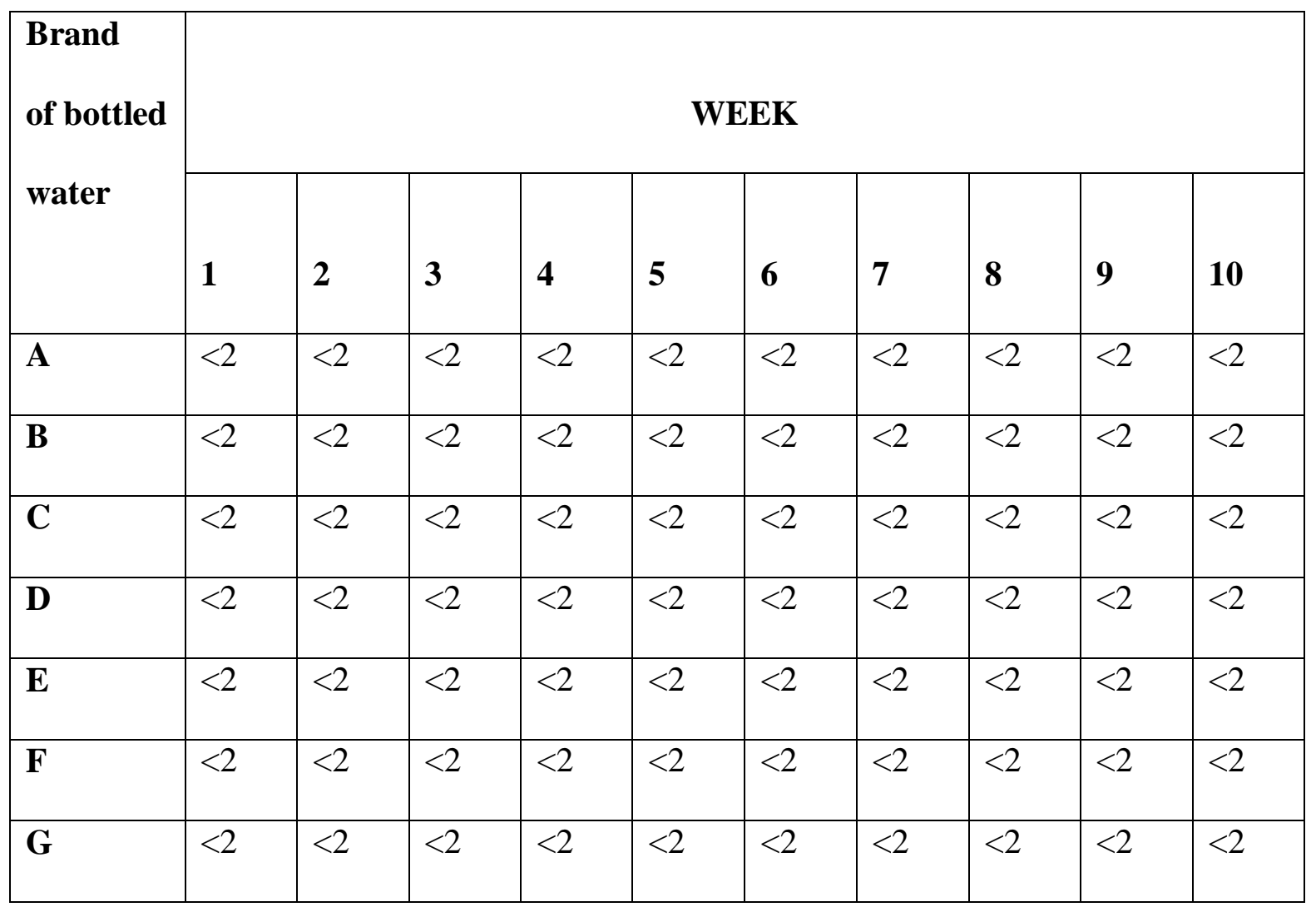




\section{REFERENCES}

1. Warburton DW The microbiological safety of bottled waters. In: Farber JM and Ewen ED (eds.) Safe handling of foods. Marcel Dekker Inc. New York. 2000.

2. Li WMK, Lacroix B and DA Powell The microbiological safety of bottled water in Canada, Food Safety Network, 2004.

3. Raj SD Bottled water: how safe is it? Water Environ Res 2005; 77(7):3013-8.

4. Health Canada: Drinking water guidelines 2001.

5. Calugay J Risk of contamination same for bottled and tap water. The Kingston Whig-Standard Community 2000, p.11.

6. Warburton DW, Dodds KL, Burke R, Johnston MA and PS Laffay A review of microbiological quality of bottled water sold in Canada between 1981 and 1989. Canadian Journal of Microbiology 1992; 38:12-19

7. Nsaze $\mathbf{H}$ and $\mathbf{Z}$ Babarinde Microbiological Quality of Bottled Drinking Water in the UAE and the Effect of Storage at Different Temperatures. Environ. Int. 1999; 25(1):53-57.

8. Warburton DW, Peterkin PI, Weiss KF and MA Johnston Microbiological Quality of Bottled Water Sold in Canada. Can J Microbiol 1986; 32: 891-893.

9. Blake PA, Rosenberg ML, Florencia J, Costa JB, do Prado Quintino L and EJ Gangarosa Cholera in Portugal, 1974. II. Transmission by bottled mineral water. Am. J. Epidemiol. 1977; 105(4): 344-348.

10. Obiri-Danso K, Okore-Hanson A and K Jones The microbiological quality of drinking water sold on the streets in Kumasi, Ghana. Lett. Appl. Microbiol. 2003; 37(4): 334-339.

11. Green M and T Green, Water the boom. In the good water guide ed. Green G and Green T. 1994; pp. 6-7 London: Rosendale Press.

12. Hunter PR Bottled mineral waters and other bottled waters. Microbiology Europe. 1994; 2: 8-9

13. Adenkunle LV, Sridhar MKC, Ajayi AA, Oluwade PA and JF Olawuyi An assessment of the health and social economic implications of sachet water in Ibadan Nigeria: A public health challenge. African Journal of Biomedical Research 2004; 7 (1): 5-8. 
14. Ifeanyi VO, Obiekezie SO, Udebuani AC and PN Abara Quality evaluation of sachet water sold in Port Harcourt, Nigeria. International Journal of Natural and Applied Sciences 2006; 2 (4): 332-335.

15. WHO - World Health Organization 2001. Guidelines for Drinking-Water Quality (2nd edn.). Vol 1: Microbiological Methods. World Health Organization, Geneva.

16. Smith AL Principles of Microbiology. $4^{\text {th }}$ Edition, 1985; pp. 896-906.

17. Kasenga GR The health-related microbiological quality of bottled drinking water sold in Dar es Salaam, Tanzania. J Water Health 2007; 5(1):179-85.

18. Okagbue RN, Dlamini NR, Siwela M and F Mpofu Microbiological quality of water processed and bottled in Zimbabwe. Afr J Health Sci. 2002; 9(1-2):99103.

19. Bharath J, Mosodeen M, Motilal S, Sandy S, Sharma S, Tessaro T, Thomas K, Umamaheswaran M, Simeon D and AA Adesiyun Microbial quality of domestic and imported brands of bottled water in Trinidad. Int J Food Microbiol. 2003; 25; 81(1):53-62.

20. Anonymous Council Directive of 3 November 1998 concerning the Quality of water intended for human consumption (98/83/EC0. Official Journal of the European Communities 1980; L330, 32-54

21. Ehlers MM, van Zyl WB, Pavlov DN and EE Muller Random Survey of the microbial quality of bottled water in South Africa. Water SA. 2004; 30 (2): 203210.

22. Ducluzeau R, Bochand JM and S Dufresne Longevity of various bacterial strains of intestinal origin in gas-free mineral water. Eur J Appl Microbiol. 2002; 3:227-236.

23. Balow A Topley and Wilson microbiology and microbial infection. Brain and Derden 1998; $9^{\text {th }}$ Edition, Vol 2 systematic bacteriology, pp. 351-364 